\title{
The zinc content of rice in Bangladesh: relationship to soil, production methods, diets and the zinc status of children
}

\author{
A. B. Mayer ${ }^{1}$, M. C. Latham ${ }^{1}$, J. M. Duxbury ${ }^{2}$, N. Hassan $^{3}$, E. A. Frongillo ${ }^{1}$ and T. Biswas ${ }^{1}$ \\ ${ }^{1}$ Nutritional Sciences, Cornell University, Ithaca, NY 14853 USA, ${ }^{2}$ Crop and Soil Sciences, Cornell University, Ithaca, \\ NY 14853 USA and ${ }^{3}$ Nutrition and Food Science, Dhaka University, Bangladesh
}

\begin{abstract}
The aim was to explore connections between soil, crop and human micronutrient deficiencies. Zinc was used as an example of a nutrient that is deficient both in soils and humans in Bangladesh. Samples of soil and unpolished rice were collected from farmers in six districts in two seasons. A diet and nutrition survey was undertaken in 156 households in four villages in four districts and included 24-h dietary recall, collection of rice and samples of children's hair. Inductively coupled plasma atomic emission spectrometry was used for mineral analysis. Fifty one percent of the soil samples had $<0.8 \mathrm{ppm}$ available zinc, a critical level for rice production. During both seasons, soil zinc was significantly and positively related to unpolished rice zinc after controlling for soil $\mathrm{pH}(P<0.001$ for irrigated and $P<0.05$ for monsoon season). Milling removed from 10 to $50 \%$ of the unpolished rice zinc. The polished rice zinc ranged from 0.70 to $2.39 \mathrm{mg} / 100 \mathrm{~g}$ (mean $=1.29 ; \mathrm{SD}=0.35)$. With $68 \%$ of the children's dietary zinc provided by rice, the total dietary zinc intake of children was highly influenced by the variability in the rice zinc. The children's hair zinc was positively related to the zinc content of the rice they consumed $(P<0.01)$. It follows that optimizing the zinc content of rice through changes in agriculture and processing would be useful for tackling human zinc deficiency.
\end{abstract}

This work was supported by USAID Soil Management-Collaborative Research Support Program. 